\title{
Descriptive epidemiology of ependymal tumours in the United States
}

\author{
J L Villano*,1, C K Parker ${ }^{2}$ and T A Dolecek ${ }^{3}$ \\ ${ }^{1}$ Departments of Medicine and Neurology, Division of Oncology, University of Kentucky, Lexington, KY, USA; ${ }^{2}$ Department of \\ Medicine; and ${ }^{3}$ Division of Epidemiology and Biostatistics and Institute for Health Research and Policy, School of Public Health, \\ University of Illinois at Chicago, Chicago, IL, USA
}

Background: Ependymomas are rare primary gliomas that commonly affect both children and adults, but unique as survival is worse in children.

Methods: Data on brain and central nervous system primary malignant and non-malignant ependymal tumours from the Central Brain Tumor Registry of the United States analytic data set and primary malignant ependymal tumours from the SEER 13 registries research data file were used to evaluate incidence and survival, respectively.

Results: The 2004-2009 average annual age-adjusted incidence rate of ependymal tumours was 0.41/100 000. Spinal cord/cauda equina was the primary site at diagnosis for $50-60 \%$ of ependymal tumours in adult age groups in contrast to about $20 \%$ in children and adolescents. Ependymoma was the most frequent histology in all age groups; however, anaplastic ependymoma comprised about $30 \%$ in cases $0-19$ years of age compared with about $3-5 \%$ in adult age groups. Overall, relative survival was favourable with rates at $\sim 85 \%$ and $75 \%$ at 3 and 10 years post diagnosis, respectively. However, children and adolescents, the oldest adult age group, cases diagnosed with anaplastic ependymoma and/or tumour location in a brain site had lowest survival rates.

Conclusion: Paediatric cases had worse outcomes compared with adults for numerous reasons including having a higher percentage of anaplastic ependymomas and greater percentage of cases of intracranial disease.

Ependymal tumours are neuroectodermal tumours that although rare have a significant impact on the quality of life and mortality (Thuppal et al, 2006). These tumours are derived from ependymal cells that line cerebrospinal fluid (CSF)-filled ventricles, spinal canal and filum terminale (Del Bigio, 1995). A type of neuroglia, ependymal cells are essential for CSF production and have a cuboidal, multi-ciliated morphology (Brody et al, 2000). In murine studies, ependymal cells are derived from radial glial prenatally with continued differentiation and maturation of cilia during early postnatal period (Spassky et al, 2005; Taylor et al, 2005).

Ependymal tumours range in WHO grade classification from I-III (Louis, 2007). WHO grade I tumours include myxopapillary ependymoma and subependymomas. Myxopapillary ependymomas are almost exclusively located in the lower portion of the spinal cord/cauda equina, while subependymomas are often found in the ventricular wall (Scheithauer, 1978; Sonneland et al, 1985). WHO grade II tumours grouped as 'ependymoma' include cellular ependymoma, clear cell ependymoma, tanycytic ependymoma and papillary ependymoma. Anaplastic ependymomas are classified as WHO grade III and are commonly intracranial while WHO grade II ependymomas are found mostly in the upper spinal cord and/or are intracranial (Mork and Loken, 1977; Marks and Adler, 1982; Guyotat et al, 2002). Ependymal tumours exhibit either malignant or borderline malignant behaviour.

The goal of our study is to further characterise ependymal tumours with insights from incidence and survival data derived from population-based cancer registries in the United States.

\section{MATERIALS AND METHODS}

The study evaluated population-based registry data on cases diagnosed with ependymal tumours defined as histology codes

*Correspondence: Dr JL Villano; E-mail: jlvillano@uky.edu

Received 2 January 2013; revised 10 April 2013; accepted 14 April 2013; published online 9 May 2013

(c) 2013 Cancer Research UK. All rights reserved 0007-0920/13 
9383, 9391-9394 in the brain or the central nervous system (CNS) primary sites C70.0-C72.9, C75.1-C75.3 (International Classification of Diseases for Oncology Third Edition (ICD-O-3)) (Fritz and World Health Organization, 2000). The data source for incidence was the Central Brain Tumor Registry of the United States (CBTRUS)

Table 1. Primary brain and CNS ependymal tumour incidence statistics for selected characteristics, CBTRUS ${ }^{\mathrm{a}}$ analytic file, 2004-2009

\begin{tabular}{|l|c|c|c|c|c|c|}
\hline & Count & $\%^{\mathrm{b}}$ & Rate $^{\mathrm{c}}$ & $\mathbf{s . e .}$ & $\begin{array}{c}\mathrm{m}: \mathrm{b} \\
\mathbf{r r}^{\mathrm{d}}\end{array}$ & $\begin{array}{c}\% \\
\text { Tumours }^{\mathrm{a}}\end{array}$ \\
\hline Total & 7303 & 100.0 & 0.41 & 0.005 & $1.80^{\mathbf{e}}$ & 2.0 \\
\hline Gender & 4022 & 55.1 & 0.46 & 0.007 & $1.47^{\mathbf{e}}$ & 2.6 \\
\hline Male & 3281 & 44.9 & 0.37 & 0.006 & $2.35^{\mathbf{e}}$ & 1.6 \\
\hline Female & 6357 & 87.0 & 0.44 & 0.006 & $1.72^{\mathbf{e}}$ & 2.1 \\
\hline Race group & 556 & 7.6 & 0.25 & 0.011 & $2.71^{\mathbf{e}}$ & 1.5 \\
\hline White & 49 & 0.7 & 0.26 & 0.038 & 1.58 & 2.5 \\
Black & 174 & 2.4 & 0.20 & 0.016 & $3.07^{\mathbf{e}}$ & 1.8 \\
AlAN &
\end{tabular}

\section{Ethnicity}

\begin{tabular}{|l|c|c|c|c|c|c|}
\hline Hispanic & 850 & 11.6 & 0.34 & 0.013 & $2.49^{\mathbf{e}}$ & 2.4 \\
Non-Hispanic & 6453 & 88.4 & 0.43 & 0.005 & $1.72^{\mathbf{e}}$ & 1.9 \\
\hline
\end{tabular}

Age group (years)

$0-19$

20-44

$45-64$

$65+$

\begin{tabular}{c|c|c|c|c|c}
1345 & 18.4 & 0.28 & 0.008 & $5.58^{\mathrm{e}}$ & 5.4 \\
2473 & 33.9 & 0.41 & 0.008 & $1.42^{\mathrm{e}}$ & 3.5 \\
2569 & 35.2 & 0.59 & 0.012 & $1.49^{\mathrm{e}}$ & 2.0 \\
916 & 12.5 & 0.42 & 0.014 & $1.52^{\mathrm{e}}$ & 0.6
\end{tabular}

\section{Behaviour}

\begin{tabular}{|l|l|l|l|l|l|l|}
\hline Malignant & 4683 & 64.1 & 0.27 & 0.004 & NA & 3.6 \\
Borderline malignant & 2620 & 35.9 & 0.15 & 0.003 & NA & 1.1 \\
\hline
\end{tabular}

\section{Histology}

\begin{tabular}{|l|c|c|c|c|c|c|}
\hline $\begin{array}{l}\text { Ependymoma } \\
\begin{array}{l}\text { Anaplastic } \\
\text { ependymoma }\end{array}\end{array}$ & 3968 & 54.3 & 0.22 & 0.004 & NA & NA \\
$\begin{array}{l}\text { Myxopapillary } \\
\text { ependymoma } \\
\begin{array}{l}\text { Subependymoma } \\
\text { suben }\end{array}\end{array}$ & 1677 & 23.0 & 0.10 & 0.002 & NA & NA \\
\hline
\end{tabular}

\begin{tabular}{|c|c|c|c|c|c|c|}
\hline \multicolumn{7}{|l|}{ Primary site } \\
\hline $\begin{array}{l}\text { Spinal cord/cauda } \\
\text { equina }\end{array}$ & 3806 & 52.1 & 0.22 & 0.003 & $1.25^{\mathrm{e}}$ & 33.6 \\
\hline Brain & 3381 & 46.3 & 0.19 & 0.003 & $2.78^{e}$ & 2.4 \\
\hline Brain stem & 980 & 13.4 & 0.06 & 0.002 & $2.64^{e}$ & 16.6 \\
\hline Brain lobes & 538 & 7.4 & 0.03 & 0.001 & $8.64^{e}$ & 0.7 \\
\hline Brain, NOS & 671 & 9.2 & 0.04 & 0.001 & $5.40^{e}$ & 1.8 \\
\hline Ventricle & 863 & 11.8 & 0.05 & 0.002 & 0.99 & 20.0 \\
\hline Cerebellum & 265 & 3.6 & 0.02 & 0.001 & $9.31^{\mathrm{e}}$ & 2.6 \\
\hline $\begin{array}{l}\text { Other brain/CNS } \\
\text { sites }\end{array}$ & 116 & 1.6 & 0.01 & 0.001 & $2.77^{e}$ & 0.1 \\
\hline
\end{tabular}

Abbreviations: $\mathrm{AI} A \mathrm{~N}=$ American Indian/Alaska Native; $\mathrm{API}=\mathrm{Asian}$ or Pacific Islander; CBTRUS = Central Brain Tumor Registry of the United States; CNS = central nervous system; $\mathrm{NA}=$ not applicable; $\mathrm{NOS}=$ not otherwise specified.

a Percent ependymal tumours of all malignant and non-malignant brain and CNS tumours, CBTRUS, 2004-2009.

bercent total cases.

${ }^{c}$ Rates are per 100000 and age-adjusted to the 2000 US standard population.

$d_{m}: b$ rr malignant to borderline malignant rate ratio.

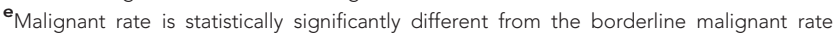
$(P<0.05)$. analytic file, 1995-2009. Survival estimates were made using the SEER 13 registries research file for 1992-2009 (SEER, 2011a).

The CBTRUS analytic file consists of population-based incidence data on all primary brain and CNS tumours collected by 49 central cancer registries (Dolecek et al, 2012). Analyses were conducted using 2004-2009 data allowing the evaluation of both malignant and non-malignant ependymal tumours, given that the Benign Brain Tumor Cancer Registries Amendment Act (Public Law 107-260) was implemented in 2004. Long-term trends were assessed on a subset with primary malignant ependymal tumours for diagnosis years 1995-2009. The CBTRUS 1995-2009 analytic file captures incidence occurring over $97 \%$ of the US population.

For the estimation of survival rates, all primary malignant ependymal tumours in brain or CNS primary sites from the SEER 13 registries research file, April 2012, were evaluated for cases diagnosed from 1992 through 2009 (SEER, 2011b). The SEER 13 registries represent $\sim 14 \%$ of the US population.

Ependymal tumour groups were defined in accordance with the WHO Classification of Tumours of the Central Nervous Systems (Louis, 2007). Categorical classifications by ICD-O-3 histology/ behaviour codes include: ependymoma (9391/3 cellular ependymoma, clear cell ependymoma and tanycytic ependymoma, and 9393/3 papillary ependymoma); anaplastic ependymomas (9392/3); myxopapillary (9394/1) and subependymomas (9383/1).

Demographic characteristics evaluated were gender; race (white; black; American Indian/Alaska Native; Asian; or Pacific Islander), ethnicity (Hispanic; non-Hispanic) and selected age groups. Age groups were based on accepted groupings, for example, 0-19 for children and adolescents, and arbitrary within adults to facilitate analysis. Tumour histology, primary site and behaviour (malignant and borderline malignant) patterns were assessed.

Frequencies, incidence rates, rate trends and relative survival rates were estimated using SEER ${ }^{\star}$ Stat 8.0.2 software (2011). Institutional Review Board approval was obtained under expedited review for research using the CBTRUS analytic file.

\section{RESULTS}

Population-based incidence statistics for all primary ependymal tumours are presented in Table 1 and Supplementary Tables 1-3. A total of 7303 ependymal tumours (4683 malignant and 2620 borderline malignant) were identified with an average annual

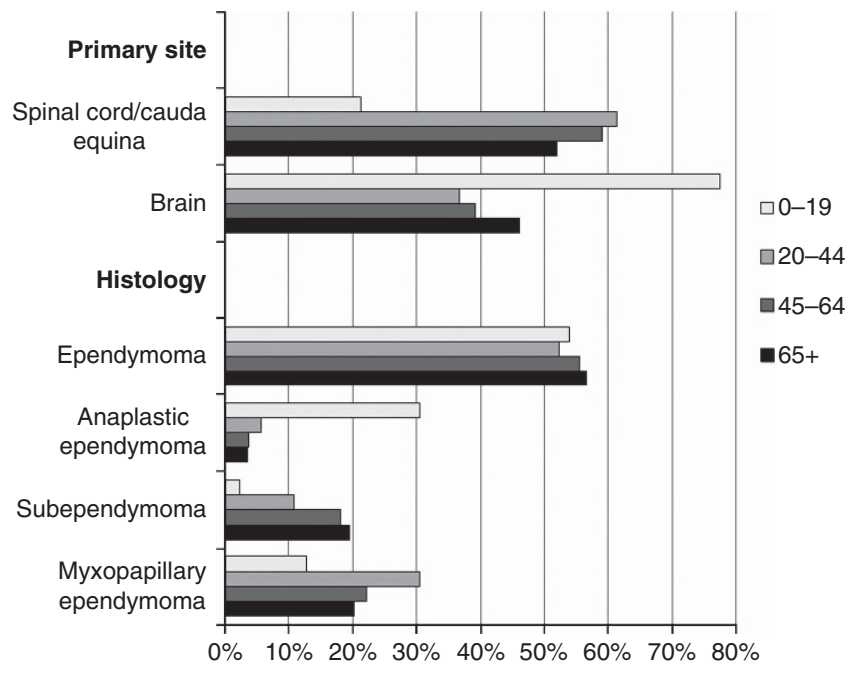

Figure 1. Distribution of age groups in site and histology categories for all primary brain and CNS ependymal tumours, CBTRUS analytic file, 2004-2009. 
age-adjusted rate (AAR) of 0.41 per 100000 (0.27, malignant and 0.15 , borderline malignant). Rates were higher in males than in females, whites than in other race groups and non-Hispanics compared with Hispanics. Among age groups, the highest rates were observed in age group 45-64 years. Most notable is the incidence rate ratio (IRR) of more than five times malignant to borderline malignant tumours for child/adolescent ages $0-19$ years compared with an observed IRR of about 1.5 in adult age groups.

Ependymoma had the highest count and AAR followed by myxopapillary ependymoma, subependymoma and anaplastic ependymoma. Myxopapillary ependymoma represented approximately two-thirds and subependymoma the remaining third of borderline malignant tumours, while about $85 \%$ and $15 \%$ of malignant tumours were ependymoma and anaplastic ependymoma, respectively.
About half of all ependymal tumours were diagnosed in the spinal cord/cauda equina and the remaining half in the brain and other nervous system sites. However, the proportional primary site distribution for borderline malignant ependymal tumours was $64 \%$ spinal cord/cauda equina and $35 \%$ combined brain sites (Supplementary Table 1).

Site and histology patterns differed by age at diagnosis as shown in Figure 1. Whereas $50 \%-60 \%$ of ependymal tumours in adult ages were located in the spinal cord/cauda equine, only about $20 \%$ were found in the spinal cord/cauda equine primary site for children/adolescents. As shown in Supplementary Figure 1, the proportions of ependymal tumours diagnosed in the brain sites for the age group $0-19$ years substantially exceeded those observed for adult age groups with the exception of ventricle. Among adult age groups, ventricle and cerebellum were the brain sites where

Table 2. Relative survival rates ${ }^{a}$ of primary malignant brain and CNS ependymal tumours for selected characteristics, SEER 13 registries research data, $1992-2009^{b}$

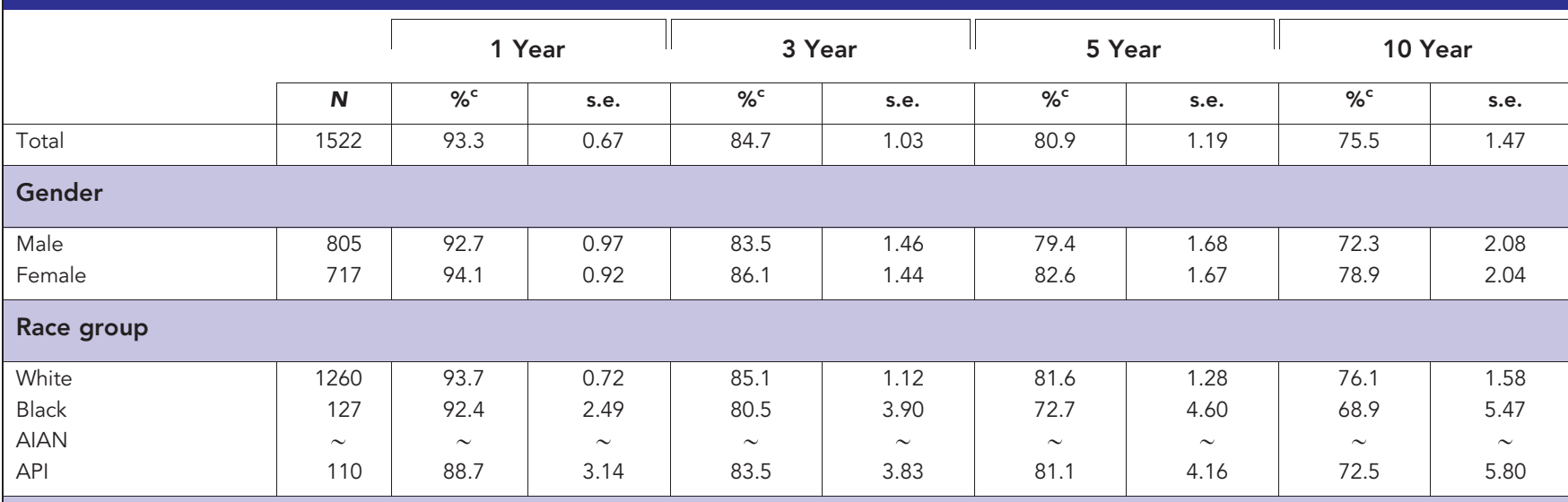

\begin{tabular}{|l|r|r|r|r|r|r|r|r|r|}
\hline Ethnicity \\
\hline Hispanic & 268 & 92.1 & 1.72 & 82.7 & 2.58 & 78.6 & 2.97 & 71.4 & 3.60 \\
Non-Hispanic & 1254 & 93.6 & 0.73 & 85.1 & 1.12 & 81.4 & 1.29 & 76.3 & 1.61 \\
\hline
\end{tabular}

\begin{tabular}{|c|c|c|c|c|c|c|c|c|c|}
\hline \multicolumn{10}{|c|}{ Age group (years) } \\
\hline 0-19 & 429 & 91.9 & 1.34 & 77.9 & 2.12 & 71.0 & 2.39 & 62.5 & 2.76 \\
\hline 20-44 & 502 & 95.2 & 0.98 & 91.4 & 1.35 & 89.8 & 1.51 & 86.5 & 1.89 \\
\hline $45-64$ & 454 & 94.0 & 1.19 & 87.8 & 1.76 & 83.7 & 2.15 & 81.8 & 2.50 \\
\hline $65+$ & 137 & 87.6 & 3.11 & 72.2 & 4.75 & 70.6 & 5.00 & 53.2 & 7.46 \\
\hline
\end{tabular}

Histology

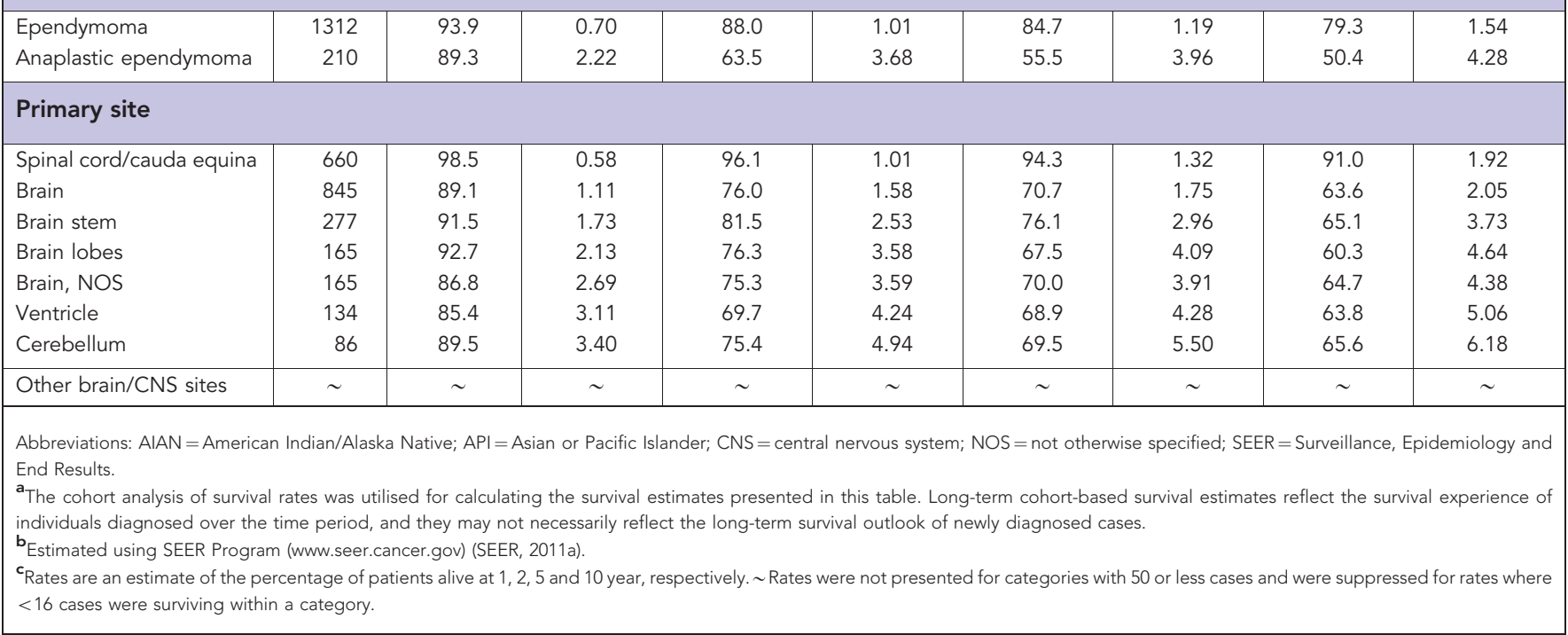


proportional increases were observed with increasing age. The brain lobes site showed progressively lower proportions of cases with advancing age group.

The distribution by histology also differed by children/ adolescent and adult age groups. While ependymoma was the most frequent histology in all age groups, anaplastic ependymoma was about six times more frequent in children and adolescents than adults, while the reverse pattern was apparent for subependymomas and myxopapillary ependymomas. For adult age groups, the proportional distribution pattern for subependymoma increased with advancing age, whereas decreases with age were observed for myxopapillary ependymoma.

Ependymal tumours exhibit a bimodal age distribution showing a peak in the $0-4$ year age group declining through the early adolescent years and then rising to a second peak in the 55-59 year age group with the oldest age groups. Supplementary Figure 2 graphically shows the bimodal age distribution.

Supplementary Table 3 shows findings from the analysis of malignant ependymal tumour incidence for CBTRUS, 1995-2009.Trend analyses showed primary malignant ependymal tumour incidence rates to increase and in most instances significantly for most categories in gender, race, age, histology and primary site groups.

Relative survival estimates were made for a total of 1522 malignant ependymal tumour cases reported to the 13 SEER registries during 1992-2009 (Table 2). Overall, relative survival was $\sim 93 \%, 85 \%, 80 \%$ and $75 \%$ at $1,3,5$ and 10 years post diagnosis, respectively. Poorer relative survival was observed for the youngest and oldest age groups, cases diagnosed with anaplastic ependymoma and/or tumours located in the brain sites. Additional relative survival estimate comparisons are graphically presented in Supplementary Figures 3-5.

\section{DISCUSSION}

Our comprehensive evaluation reaffirms findings from previous studies (Rodriguez et al, 2009; McGuire et al, 2009a,b; Amirian et al, 2012; Bishop et al, 2012; Crocetti et al, 2012; Dolecek et al, 2012). Outcomes were generally favourable except for age groups $0-19$ years and $65+$ years, anaplastic ependymomas and tumour location in the brain site.

Children are more often diagnosed with anaplastic ependymomas and with tumours located in the brain sites. Furthermore, when the diagnosis is WHO grade II ependymoma, children fare worse than adults in the 20-44 and 45-64 year age groups. This is uncommon as most cancers of the same type and grade have improved outcomes in children compared with adults (Dolecek et al, 2012). Potential explanations include: (1) paediatric and adult cases having different biologically based tumours with gain of chromosome $1 \mathrm{q}$ and the absence of chromosomal imbalances as a marker for more aggressive disease (Korshunov et al, 2010; Wani et al, 2012), (2) although morphologically similar systematic bias by pathologists to report a better tumour grade/ histology in paediatric cases, which has been demonstrated for classification of oligodendrogliomas (McCarthy et al, 2008); (3) differences in treatment, such as less radiation use in children (Koshy et al, 2011); and (4) differences in tumour biology based on location-genetic testing demonstrate subsets of ependymomas exhibit distinct patterns of chromosomal mutations and gene expression based on anatomical site (Spassky et al, 2005; Taylor et al, 2005).

The poorer relative survival for elderly cases may, in part, be explained by the fact that proportionately more diagnoses occurred in the brain sites among elderly than younger adult age groups (Supplementary Tables 2b, c and d). Our study has limitations, including the lack of detailed clinical data that may impact survival which, if available, could also shed light on this observation.

Insights from population-based incidence and survival analyses afford an opportunity to better understand the impact of site and histology patterns on outcomes associated with ependymal tumours and inform future research.

\section{ACKNOWLEDGEMENTS}

We thank Bridget J McCarthy, PhD, for discussions that led to initial analysis and for being a good friend, colleague and mentor. Funding for Therese Dolecek was in part by the Central Brain Tumor Registry of the United States (CBTRUS), which received support from the American Brain Tumor Association, the National Brain Tumor Society, the Pediatric Brain Tumor Foundation, the Division of Cancer Control and Population Sciences, National Cancer Institute, National Institutes of Health, Department of Health and Human Services, under contract no. HHSN261201000576P, and from the Cooperative Agreement 1U58DP003831 from the Centers for Disease Control and Prevention.

\section{REFERENCES}

Amirian ES, Armstrong TS, Gilbert MR, Scheurer ME (2012) Predictors of survival among older adults with ependymoma. J Neurooncol 107: 183-189.

Bishop AJ, McDonald MW, Chang AL, Esiashvili N (2012) Infant brain tumors: incidence, survival, and the role of radiation based on Surveillance, Epidemiology, and End Results (SEER) Data. Int J Radiat Oncol Biol Phys 82: 341-347.

Brody SL, Yan XH, Wuerffel MK, Song SK, Shapiro SD (2000) Ciliogenesis and left-right axis defects in forkhead factor HFH-4-null mice. Am J Respir Cell Mol Biol 23: 45-51.

Crocetti E, Trama A, Stiller C, Caldarella A, Soffietti R, Jaal J, Weber DC, Ricardi U, Slowinski J, Brandes A (2012) Epidemiology of glial and nonglial brain tumours in Europe. Eur J Cancer 48: 1532-1542.

Del Bigio MR (1995) The ependyma: a protective barrier between brain and cerebrospinal fluid. Glia 14: 1-13.

Dolecek TA, Propp JM, Stroup N, Kruchko C (2012) CBTRUS Statistical Report: primary brain and central nervous system tumors diagnosed in the United States in 2005-2009. Neurooncol 14(suppl 5): v1-v49.

Fritz AG. World Health Organization (2000) International Classification of Diseases for Oncology: ICD-O. 3rd edn (World Health Organization: Geneva, Switzerland.

Guyotat J, Signorelli F, Desme S, Frappaz D, Madarassy G, Montange MF, Jouvet A, Bret P (2002) Intracranial ependymomas in adult patients: analyses of prognostic factors. J Neurooncol 60: 255-268.

Korshunov A, Witt H, Hielscher T, Benner A, Remke M, Ryzhova M, Milde T, Bender S, Wittmann A, Schottler A, Kulozik AE, Witt O, von Deimling A, Lichter P, Pfister S (2010) Molecular staging of intracranial ependymoma in children and adults. J Clin Oncol 28: 3182-3190.

Koshy M, Rich S, Merchant TE, Mahmood U, Regine WF, Kwok Y (2011) Post-operative radiation improves survival in children younger than 3 years with intracranial ependymoma. J Neurooncol 105: 583-590.

Louis DN. International Agency for Research on Cancer \& World Health Organization (2007) WHO Classification of Tumours of the Central Nervous System. 4th edn. (International Agency for Research on Cancer: Lyon, France.

Marks JE, Adler SJ (1982) A comparative study of ependymomas by site of origin. Int J Radiat Oncol Biol Phys 8: 37-43.

McCarthy BJ, Propp JM, Davis FG, Burger PC (2008) Time trends in oligodendroglial and astrocytic tumor incidence. Neuroepidemiology 30: 34-44.

McGuire CS, Sainani KL, Fisher PG (2009a) Both location and age predict survival in ependymoma: a SEER study. Pediatr Blood Cancer 52: 65-69.

McGuire CS, Sainani KL, Fisher PG (2009b) Incidence patterns for ependymoma: a Surveillance, Epidemiology, and End Results study. J Neurosurg 110: 725-729. 
Mork SJ, Loken AC (1977) Ependymoma: a follow-up study of 101 cases. Cancer 40: 907-915.

Rodriguez D, Cheung MC, Housri N, Quinones-Hinojosa A, Camphausen K, Koniaris LG (2009) Outcomes of malignant CNS ependymomas: an examination of 2408 cases through the Surveillance, Epidemiology, and End Results (SEER) database (1973-2005). J Surg Res 156: 340-351.

Scheithauer BW (1978) Symptomatic subependymoma. Report of 21 cases with review of the literature. J Neurosurg 49: 689-696.

SEER (2011a) http://seer.cancer.gov, SEER ${ }^{\star}$ Stat Database: Incidence-SEER 13 Regs Research Data, Nov 2010 Sub (1992-2008) (Katrina/Rita Population Adjustment) - Linked to County Attributes-Total U.S., 19692009 Counties, National Cancer Institute, DCCPS, Surveillance Research Program, Cancer Statistics Branch, released April 2011 (updated 28 October 2011), based on the November 2010 submission.

SEER (2011b) Surveillance Research Program SEER ${ }^{*}$ Stat 8.0.2 software. National Cancer Institute; www.seer.cancer.gov/seerstat.

Sonneland PR, Scheithauer BW, Onofrio BM (1985) Myxopapillary ependymoma. A clinicopathologic and immunocytochemical study of 77 cases. Cancer 56: 883-893.

Supplementary Information accompanies this paper on British Journal of Cancer website (http://www.nature.com/bjc)
Spassky N, Merkle FT, Flames N, Tramontin AD, Garcia-Verdugo JM, Alvarez-Buylla A (2005) Adult ependymal cells are postmitotic and are derived from radial glial cells during embryogenesis. J Neurosci 25: 10-18.

Taylor MD, Poppleton H, Fuller C, Su X, Liu Y, Jensen P, Magdaleno S, Dalton J, Calabrese C, Board J, Macdonald T, Rutka J, Guha A, Gajjar A, Curran T, Gilbertson RJ (2005) Radial glia cells are candidate stem cells of ependymoma. Cancer Cell 8: 323-335.

Thuppal S, Propp J M, McCarthy B J (2006) Average years of potential life lost in those who have died from brain and CNS tumors in the USA. Neuroepidemiology 27: 22-27.

Wani K, Armstrong TS, Vera-Bolanos E (2012) A prognostic gene expression signature in infratentorial ependymoma. Acta Neuropathol 123: 727-738.

This work is published under the standard license to publish agreement. After 12 months the work will become freely available and the license terms will switch to a Creative Commons AttributionNonCommercial-Share Alike 3.0 Unported License. 